\title{
Shipwreck: A Crisis with Challenging Solutions
}

\author{
Nikolaos P. Ventikos \\ School of Naval Engineering \& Marine Architecture, Laboratory for Maritime Transport, Maritime Risk Group \\ National Technical University of Athens \\ Athens, Zografou, 15780, Greece \\ Email: niven@deslab.ntua.gr \\ Alexandros Koimtzoglou \\ School of Naval Engineering \& Marine Architecture, Laboratory for Maritime Transport, Maritime Risk Group \\ National Technical University of Athens \\ Athens, Zografou, 15780, Greece \\ E-mail: alexkoim@gmail.com \\ Konstantinos Louzis \\ School of Naval Engineering \& Marine Architecture, Laboratory for Maritime Transport, Maritime Risk Group \\ National Technical University of Athens \\ Athens, Zografou, 15780, Greece \\ E-mail: konstantinos.lusis@gmail.com \\ Received 26 May 2014 \\ Accepted 30 July 2014
}

\begin{abstract}
In this paper, we deal with the subject of shipwreck removal and the methods that are employed during removal operations. We use a case study to illustrate the stages of these operations as well as the parameters that affect the process. Furthermore, we outline a number of different scenarios of the most common techniques in order to demonstrate which one is the better fit for the particular case. The purpose of this paper is to highlight the difficulties that arise in shipwreck removal operations and offer a structured methodology for the planning stage of such a process.
\end{abstract}

Keywords: shipwrecks, wreck removal operation, wreck removal factors.

\section{Introduction}

Shipwrecks are a growing concern for maritime authorities and port states around the globe either because they inhibit navigation or they pose an environmental threat due to leaks of toxic substances such as oil. Removing the wreck is the best solution to both problems, even if in some cases such an operation is not cost-effective.

Wreck removal is a field with high levels of uncertainty and a large number of associated risk factors. Additionally, because each case is unique there is great difficulty in formalizing the process, which is 
the reason only general instructions can be provided. Furthermore, every shipwreck is a challenge for the salvors due to the fact that many parameters, which are also interdependent on each other, should be taken into account.

This paper attempts to highlight the main parameters of a wreck removal operation, as well as to present the challenges faced and the risks assumed by salvors during wreck removal operations, by examining an illustrative case study. Another goal of this paper is the definition of a framework for the preliminary assessment of different wreck removal methods.

\section{Literature Review}

The concern over the environmental impact of sunken shipwrecks has been sparked the last few years mainly due to observed oil leaks that have been connected to wrecks such as the SS Jacob Luckenbach ${ }^{1}$ and the USS Mississinewa ${ }^{2}$.

This has led to the identification of shipwreck locations and the development of dedicated databases with international geographical scope such as the work in Ref. (3) as well regionally focused studies. Such studies are the work in Ref. (4) that focuses on the Pacific region, the work in Ref. (5) that focuses on the Skagerrak region of Sweden and Ref. (6), where a database of shipwrecks in Greece has been developed. The same studies have dealt with the environmental risks connected to shipwrecks, which stem mainly from the leak of residual oil, as well as with developing risk estimating methodologies in order to rank the impact of each shipwreck and aid in the decision of allocating resources. Recent efforts in this field are focusing on developing an acceptable general risk framework for shipwrecks. Such an effort is described in Ref. (7), which also compares the existing risk estimating models for shipwrecks.

Removing the wreck is the most drastic but also most effective way of dealing with all associated risks, either navigational or environmental. The available literature on the subject of wreck removal offers a detailed description of the theoretical and practical tools used by the salvors in these kinds of operations. Manuals such as Ref. (8) and Ref. (9) cover a wide array of subjects from elements of naval architecture for the salvage engineer and rigging systems to environmental forces and surveys of the shipwreck. However, the planning and wreck removal method selection has not been formalized beyond some simple and general guidelines as to how they might be implemented.

\section{The environment of a wreck removal operation}

The weather, the wind force, the sea and the seabed are the factors that define the environment of a wreck removal operation. Each one of them can determine the method to be applied and lead an operation to failure, or contribute to its abortion altogether. Although the estimation of these factors is difficult, they must be taken into consideration to conclude the feasibility of the operation of interest. On the other hand, there are circumstances that some environmental factors can be beneficial for an operation, for example, the salvage of a stranded ship by taking advantage of the tide.

\subsection{Weather}

Weather is a very important factor for a wreck removal operation, because it will define when or even if the operation will commence. Choosing the proper time frame for the operation, e.g. the season of year, may reduce its overall expenses and duration.

Towards this goal, the improved accuracy of the weather forecasts is a valuable tool for the proper organization of the wreck removal operation.

\subsection{Wind force}

The force of the wind is an important environmental factor, because when the shipwreck has been lifted above the surface of the sea it has a high exposed wind profile area. Moreover, the stability of the equipment used for this kind of operations such as derricks, barges and support ships can be greatly affected by the wind. Therefore the need for appropriate anchorage systems arises.

The accelerations induced by the wind increase the risk level both for the integrity of the used equipment and for the safety of the salvors at work.

The only precaution against the wind is to know the operational limits of the equipment and when to halt the operation. 


\subsection{The sea}

The environment surrounding a shipwreck can affect a wreck removal operation through various parameters, the most important of which are listed below:

- Waves,

- Currents,

- Water resistance,

- Buoyancy.

\subsubsection{Waves}

The accelerations induced by the waves to the support ships working on the surface affect the shipwreck. Therefore, depending on the magnitude of the waves an operation can be either extremely dangerous or even impossible. However, sometimes wreck removal operations must be conducted even under heavy weather, as was the case of the submarine Kursk. ${ }^{10}$

For the reasons stated above, it is vital during the planning stage of the wreck removal operation to take into account the action of the waves, depending on the geographical location and the season of the year. The data can be easily provided by the various oceanographic institutes around the globe.

\subsubsection{Currents}

The effect of currents to a wreck removal operation depends on their intensity. Strong sea currents, which are able to alter the morphology of the seabed, can change the position of the shipwreck, or even bury it. Furthermore, currents affect the maneuverability and anchoring of the equipment used for the operation, as well as the ability to effectively control the wreck during the lifting stage. However, in some cases the current may work advantageously for the operation and unbury the shipwreck from the seabed.

\subsubsection{Water resistance}

Every object that moves inside a fluid experiences resistance. The magnitude of this force depends mainly on the following factors ${ }^{11}$ : a) the projected area to the direction of the movement and, b) the squared velocity of the object. The projected area of a shipwreck is normally a number with an order of magnitude in the thousands or tens of thousands square meters. However, the main factor of the resistance force is the velocity of the wreck while ascending to the surface. A commonly used lifting velocity for a wreck removal operation is around 2-3 $\mathrm{m} / \mathrm{h}$. However, sometimes the prevailing conditions dictate faster lifting, as was the case of the submarine Kursk $^{10}$ where the lifting velocity was 10 $\mathrm{m} / \mathrm{h}$, which is considered high.

Due to the fact that usually the lifting speeds are quite low, the effect of the water resistance in a wreck removal operation should be considered negligible.

\subsubsection{Buoyancy of plating}

A buoyancy force is applied to every submerged object because of the volume of water the object displaces. The magnitude of this force is not significant for a submerged shipwreck but it reduces the required lifting capacity.

The buoyancy of the plating can be estimated by the following equation:

$$
A=V \cdot \rho \cdot g .
$$

where: $A$, is the buoyancy of the plating, in $\mathrm{N}$,

$V$, is the volume of the displaced water, in $\mathrm{m}^{3}$, $\rho$, is the density of sea water, in $\mathrm{kg} / \mathrm{m}^{3}$,

$g$, is the acceleration of gravity equal to 9.81 $\mathrm{m} / \mathrm{sec}^{2}$.

The main difficulty is the precise calculation of the displaced water volume $(V)$. A sufficient estimation for $V$ is to divide the lightship weight by the specific gravity of steel.

\subsection{The seabed}

The nature of the seabed can affect a wreck removal operation due to the following perspectives: first the sediments settling with time on the hull of the wreck (and inside the wreck) and second the seabed reaction force, the overcoming of which needs the application of a breakout force.

\subsubsection{Seabed sediments}

Every submerged object suffers from the sediments of the seabed settling on it, causing, among others, corrosion issues. Usually, sediments consist of clay, mud and microorganisms. The accumulated sedimentation may increase significantly the weight of the shipwreck. 
The best way to calculate this additional weight is to conduct an on-site survey and collect a sample from the sediments in order to determine the respective specific gravity. In cases when that is not possible, an acceptable estimation is $1,600 \mathrm{~kg} / \mathrm{m}^{3} .8$

If the calculated additional weight of the sediments is high enough, then salvors have to remove an adequate amount, by using specialized pumps.

The removal of the stern of MSC Napoli is an example that shows how sediments can affect such an operation. During this operation, the chains broke on two separate occasions because of the mud that had settled on the wreck. ${ }^{12}$

\subsubsection{Seabed reaction}

When the hull of the wreck has been embedded in the seabed, either due to the action of sea currents, or to its own weight, a reaction force is applied to the wreck. In order to unbury the wreck, a breakout force greater than the reaction of the seabed must be applied. However, in many cases the available lifting capacity is not high enough for immediate breakout and therefore it may take some time to overcome the reaction of the seabed. The exact amount of time is not fixed and depends on the parameters of each specific case.

Depending on the type of the seabed the magnitude of the required breakout force varies. This is the reason why it is important to determine the soil type of the bottom of the sea prior to setting up the wreck removal operation.

Ref. 9 offers a way of calculating the immediate breakout force as well as the time needed to detach the shipwreck from the seabed, when the lifting capacity is not high enough.

The first step is to calculate the soil bearing strength $\left(q_{u}\right)$ of the seabed.

The next step is to calculate the surface of the ship in contact with the seabed $(A)$, which is the same as the wetted surface area of the ship, calculated for a draught equal to the penetration depth of the wreck.

By estimating the soil bearing strength and the embedded surface of the wreck we are able to use the equation below to estimate the bearing capacity of the seabed:

$$
F_{q}=A \cdot q_{u} .
$$

where: $F_{q}$, is the bearing capacity of the seabed, in $\mathrm{N}$, $A$, is the area of contact with the soil, in $\mathrm{m}^{2}$, $q_{u}$, is the soil bearing strength, in $\mathrm{Pa}$.

After estimating the soil bearing capacity, the immediate breakout force that is required to unbury the shipwreck must be calculated. This calculation is based on empirical equations and therefore the results are usually overestimated. The following equation is used for calculating the immediate breakout force $\left(F_{I B}\right)$ :

$$
F_{I B}=F_{q}\left[1-0.97 e^{-2.75\left(\frac{D}{B}\right)}\right]
$$

where: $F_{q}$, is the bearing capacity of the seabed, in $\mathrm{N}$, $B$, is the equivalent breadth of the wreck, in $\mathrm{m}$, $D$, is the equivalent embedment depth of the wreck, in $\mathrm{m}$.

The area of the ship, which is in contact with the seabed $(A)$, is assumed to be a rectangular shape of the same area. The length of the equivalent rectangular $(L)$ equals the ship's length. The equivalent breadth $(B)$ is calculated as a function of the area $(A)$ and the length (L).

For calculating the equivalent embedment depth $(D)$ we need the volume of the seabed soil $(V)$ that has been displaced by the wreck. This volume is equal to the volume of displaced water at a draught equal to the embedment depth. Therefore, the equivalent depth $D$ is equal to the ratio $V / A$.

The immediate breakout force $\left(F_{I B}\right)$ is the force needed to immediately detach the shipwreck from the seabed. However, in most cases the immediate breakout force is much higher than the available lifting capacity, which means that a smaller force $\left(F_{A P}\right)$ will be applied to the shipwreck.

The applied breakout force $\left(F_{A P}\right)$ is calculated from the following formula, where negative are the forces with the same direction as weight and positive the ones with the opposite direction.

$$
F_{A P}=0.75 \cdot L C-W_{S H I P}-W_{S E D}+B_{P L} .
$$

where: $F_{A P}$, is the applied breakout force, in $\mathrm{t}$, 0.75 is a safety factor reducing the available lifting capacity ${ }^{9}$,

$L C$, is the lifting capacity, in $\mathrm{t}$,

$W_{S H I P}$, is the weight of the wreck, in t,

$W_{S E D}$, is the weight of sediments, in $\mathrm{t}$,

$B_{P L}$, is the plating buoyancy, in t. 
As a result, the detachment process will take more time, which can be estimated by the following empirical equation:

$$
t=\left(T \cdot D^{4}\right) /\left(B^{2} \cdot p\right)
$$

where: $t$, is the breakout time, in minutes,

$T$, is the breakout parameter depending on the ratio $F_{A P} / F_{I B}$ (Figure 1 ),

$D$, is the equivalent embedment depth of the wreck, in feet,

$B$, is the equivalent breadth of the wreck, in feet,

$p$, is the average breakout pressure applied to the seabed, in psf, calculated by the ratio $F_{A P} / A$.

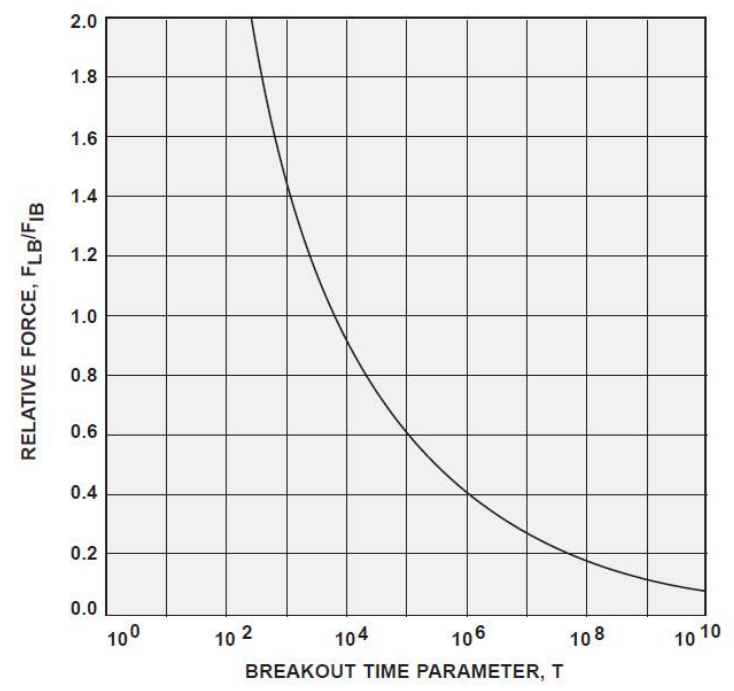

Fig. 1: Breakout time parameter as a function of relative force. ${ }^{9}$

\section{Shipwreck Removal Methods}

There are many methods used to remove a wreck, but the most commonly used are restoring buoyancy and lifting with mechanical means. The other available wreck removal methods are quite specialized and are only used on cases, where special circumstances mandate consideration of non-conventional solutions. Due to the fact that every removal operation offers unique challenges to salvors, usually the best solution is to combine various methods in order to exploit the advantages of each of one.
The selection of a wreck removal method for a particular case involves taking into account a multitude of parameters. The most important are environmental parameters, such as prevailing weather conditions and the type of the seabed, and the weight of the shipwreck, which will determine the required lifting capacity.

\subsection{Restoring buoyancy}

Most or even all compartments of a sunken ship may have been flooded with water. This means that the wreck displaces less water resulting in a significant loss of buoyancy. The basic concept behind this method is to restore the lost buoyancy of the sunken ship in order to be able to float again back on the surface. To achieve this, the flooded compartments of the ship have to be sealed and the trapped water removed, these are the two stages of the method of the restoring of buoyancy.

Sealing cracks on the hull can be achieved by using various types of mainly steel patches or cofferdams. However, depending on the hull type and material, different types of patches can be used. Some of the alternative materials for patches are: concrete, composite materials, and wood. ${ }^{13}$

After sealing the compartments, the next stage is to remove the trapped water. There are two ways of dewatering: (i) pumping and (ii) displacing the trapped water with compressed air. Both methods require the use of pumps, although the type for each one of these ways differs.

The use of compressed air requires better patching and is considered more time-consuming comparing to pumping out the water. Moreover, the air pressure inside the compartment needs to be monitored constantly to avoid either an explosion, which will occur when the internal air pressure exceeds the external hydrostatic pressure, or an implosion, which occurs when the opposite happens. The air compression dewatering method is suitable for cargo oil tanks of tanker ships, as well as fuel and water ballast tanks, because these kinds of tanks are easier to seal.

A variation of the buoyancy restoration method is induced buoyancy, which is mainly used for small ships (e.g. yachts etc.). This method uses equipment, such as balloons, pontoons and sometimes special foams ${ }^{14}$ for displacing trapped water. One of the main disadvantages of this method is the lack of control of the movement of the shipwreck while rising towards the surface. Additionally, the amount of buoyancy that is restored is 
much smaller compared to conventional buoyancy restoring methods.

\subsection{Lifting by Mechanical Means}

The second commonly used method for wreck removal operations is lifting by mechanical means. In general, the employed mechanical means are derricks, sheer legs and various lifting mechanisms, which are fitted on barges. Steel wires and chains are mainly used for attaching the lifting mechanism to the shipwreck.

The restriction of this particular method is the lifting capacity of the employed equipment. A common occurrence is the inadequacy of the available lifting capacity to lift the shipwreck in one piece, which then results in the decision to cut the shipwreck into a suitable number of pieces.

Chains or special steel wires, with high levels of hardness similar to that of diamonds, are used for the cutting process. An essential part of such an operation is to determine the length of each piece into which the wreck will be cut. For example, cutting an engine room in the middle is not preferred because objects positioned therein such as the main engine and the propeller shaft are going to make the cutting process extremely difficult and slow, resulting in delaying the overall operation.

Alternatively, a quicker but also more dangerous way of cutting a wreck into pieces is by using explosives. This option was used for cutting the wreck of the container ship MSC Napoli into two pieces. ${ }^{15}$

The advantages of lifting with mechanical means are: briefer preparation time because there is no need for sealing various compartments and the improved controllability of the shipwreck while lifting it towards the surface. Moreover, the depth of the shipwreck is not a significant restriction for the application of this method.

\subsection{Other ways of removal}

There are also other ways to remove a wreck but they are not commonly used mainly because of their ineffectiveness and the damages that can be brought on the marine environment.

Two methods, that raise environmental concerns, are burying or exploding a wreck, which are therefore used only in times of war because of their immediacy and speed.
Finally, a different method is the in situ scrapping of the wreck, which has been used in the removal of the stern section of the bulk carrier New Carissa that ran aground on a beach near Coos Bay, Oregon, United States. ${ }^{16}$

\subsection{Comparison of common methods}

Restoring buoyancy is less expensive but a more time consuming method compared to lifting a shipwreck with mechanical means; this is due to the fact that simpler equipment is used. However, the main disadvantage of restoring buoyancy is the restriction on the depth of the shipwreck because of the high values of hydrostatic pressure. For this reason, it is only used in low depths, i.e. up to about $40 \mathrm{~m}$. Another concern is the pressure inside the sealed compartments, which needs to be constantly monitored as it changes with the changes in depth during the lifting process, in order to avoid explosions or implosions. However, restoring buoyancy is a method that causes minimal damage to the hull, which is the reason that this method is also used for salvaging a sunken ship. An example of salvaging by restoring buoyancy is the case of the dry-dock FDN1, which sank off Port Blair in the Andaman Islands. ${ }^{17}$

On the other hand, while lifting a shipwreck with mechanical means requires no sealing, which simplifies the whole operation, it is essential to conduct a detailed study for rigging the wreck. Additional advantages of this method are improved controllability of the shipwreck, the lack of a need for monitoring the pressure inside the hull and higher lifting velocities, which can result in reduced durations for these operations. However, the high operating and renting cost as well as the availability of lifting equipment such as derricks and/or sheer legs are major concerns when lifting a shipwreck by mechanical means.

\section{An Illustrative Case Study}

The best way to clarify the information presented before in this paper is to examine an illustrative case study. The analysis will present the stages of a wreck removal operation and highlight the most important factors in a hands-on way of thinking.

\subsection{Defining the shipwreck}

The case study involves a passenger ship sinking near the shore due to contact with reefs which resulted cracks 
in her hull (assuming that there are no human casualties from this marine accident). Another assumption is that the wreck lies $135 \mathrm{~m}$ from the surface of the sea and the embedment depth in the seabed is $2 \mathrm{~m}$ equally across the length of the sunken vessel. The location of the shipwreck in relation to the local geomorphology and its distance from the shore is shown in Figure 2. The seabed in this location is highly inclined, which can render the operation extremely dangerous, because in case of any miscalculation the ship will sink deeper dragging the lifting equipment with her (in case this type of salvaging effort is selected). Additionally, the wreck has been lying on the seabed for a long time, which means that there will be a significant accumulation of sediments on the hull. The particulars of the shipwreck are shown in Table 1.

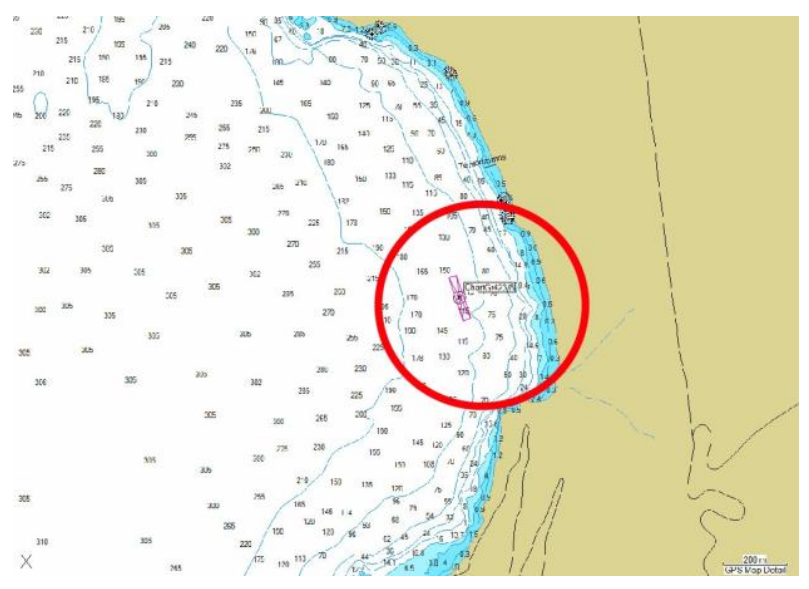

Fig. 2: The location of the illustrative wreck.

It is also assumed that the seabed around the shipwreck is viscous and consists of finely grained sand. Finally, at the time of the accident the ship had a displacement equal to $12,076 \mathrm{t}$.

Table 1: The main particulars of the shipwreck.

\begin{tabular}{clcc}
\hline & \multicolumn{1}{c}{ Data } & \multicolumn{1}{c}{ Value } \\
\hline \multirow{2}{*}{ Dimensions } & Length Overall & $L_{O A}$ & $142.95 \mathrm{~m}$ \\
& Breadth Mld. & $B$ & $24.70 \mathrm{~m}$ \\
Weight & Displacement & $\Delta$ & $12,076 \mathrm{t}$ \\
groups & Deadweight & $D W T$ & $2,139 \mathrm{t}$ \\
\multirow{2}{*}{ Volume } & Lightship & $L S$ & $9,938 \mathrm{t}$ \\
& Gross Tonnage & $G R T$ & $21152 \mathrm{gt}$ \\
Occupants & Passengers & & 1,537 \\
& Crew & & 300 \\
\hline
\end{tabular}

An important part of the planning stage of a realworld wreck removal operation would be cross checking the initial data by conducting an on-site survey. This is necessary because initial data coming from reports are either not reliable enough or might have changed due to the action of environmental factors. For example, the way the wreck lies on the seabed might have been altered by the action of waves and currents.

\subsection{Calculating the ship weight}

Determining the weight of the shipwreck is one of the most critical parts of the wreck removal operation, because it will help to decide on the possible methods to be used. For this, it is essential to know the exact displacement of the ship at the time of the accident.

Depending on the type of the ship there are certain weights that can be easily removed to decrease the weight of the shipwreck, which can sometimes prove to be cost beneficial, even though the associated initial cost might seem steep. This is due to the fact that lightering the shipwreck, prior to the removal operation, results e.g. in the use of lower capacity lifting equipment, which minimizes the total cost of the operation.

The weights to be removed in the context of this case study are the following:

- Fuels,

- Occupants and lifesaving equipment,

- Deck outfitting.

Additionally, the buoyancy of the hull plating, when the ship is in the water, needs to be taken into account in determining the required lifting capacity. In particular, the buoyancy force is subtracted from the weight of the shipwreck.

On the other hand, a sunken shipwreck has some added weights, which increase significantly the weight of the wreck and they should also be taken into account. These are the following:

- Seabed sediments,

- Water trapped in certain compartments of the hull.

Finally, when the wreck lies partially embedded in a viscous seabed, the force required to break out the hull, which equals the suction by the seabed, needs to be 
factored into the estimation of the total force required to bring the shipwreck to the surface of the sea.

\subsubsection{Weight of fuels}

The first step of the operation is to locate and collect the remaining fuels so as to avert any possible (additional) pollution while removing the wreck.

Table 2: Analysis of fuel weights.

\begin{tabular}{lrr}
\hline & $\begin{array}{c}\text { Volume } \\
\left(\mathbf{m}^{\mathbf{3}}\right)\end{array}$ & \multicolumn{1}{c}{\begin{tabular}{c}
\multicolumn{1}{c}{ (t) } \\
\hline H.F.O. 180
\end{tabular}} \\
\hline Diesel Oil & 760.11 & 437.10 \\
Lube Oil & 36.00 & 64.60 \\
Total & 572.11 & 534.10 \\
\hline
\end{tabular}

The fuel weight at the time of the accident is documented in the report of the captain and is shown in Table 2.

\subsubsection{Weight of occupants / lifesaving equipment}

Due to the assumption that all the passengers and crew were evacuated, the total weight of the wreck will be decreased by the respective weights. Moreover, the weight of the equipment used for the evacuation procedure should be subtracted as well. Taking into account the report of the captain and the particulars of the ship, these weights are equal to:

- $\quad 135.00 \mathrm{t}$ for occupants,

- $90.50 \mathrm{t}$ for the used lifesaving equipment.

Therefore, the total weight to be subtracted from the weight of the wreck equals $225.50 \mathrm{t}$.

\subsubsection{Weight of deck outfitting}

Deck outfittings include anchors and chains, which can be easily removed from the wreck and reduce the total weight of the shipwreck. From the particulars of the ship, deck outfittings are estimated to be $26.70 \mathrm{t}$ in weight.

\subsubsection{Plating Buoyancy}

As described earlier in this paper, the buoyancy of the hull plating will be estimated by calculating the displacement of the lightweight of the wreck. For this calculation, the average specific gravity of the material will be the specific gravity of steel, which is $7.689 \mathrm{t} / \mathrm{m}^{3}$, reduced to account for the lighter materials typically used in a cruise ship, such as aluminum for the superstructures. Therefore the average specific gravity, in the context of this case study, was considered equal to $6 \mathrm{t} / \mathrm{m}^{3}$. Subsequently, the volume of the water displaced by the lightweight of the wreck equals 1,656 $\mathrm{m}^{3}$.

Moreover, the specific gravity of the seawater at the location of the wreck is $1.028 \mathrm{t} / \mathrm{m}^{3}$, taking into account information from an on-site survey Substituting these values into Eq. (1) the buoyancy of the hull plating is calculated: $A=16,708 \mathrm{kN}=1,703 \mathrm{t}$.

\subsubsection{Seabed Sediments}

As also described previously in this paper, while a shipwreck rests on the seabed various microorganisms and sediments accumulate on the hull (and within its interior), significantly increasing the total weight of the wreck. It is difficult to analytically calculate the specific gravity of the sediments, without examining samples taken from the actual site. However, the specific gravity of the sediments can be approximately taken equal to $1,600 \mathrm{~kg} / \mathrm{m}^{3}{ }^{8}$ For the particular case study, the uncertainty concerning the extent of the coverage of the sediments is taken into account by calculating four different scenarios. Each scenario assumes that the sediments take up a specific percentage of the ship's volume. Therefore, the scenarios are differentiated in the weight calculated for the sediments. The scenarios range from $5 \%$ to $20 \%$ sediment extent of the ship's volume. Percentages above $20 \%$ were considered as extremely overestimated and therefore unrealistic. The results for the weight of sediments for each scenario are shown in Table 3.

Table 3: Scenarios for the weight of sediments.

\begin{tabular}{ccccc}
\hline & \multicolumn{4}{c}{ Percentage of Ship's Volume } \\
& $\mathbf{5 \%}$ & $\mathbf{1 0 \%}$ & $\mathbf{1 5 \%}$ & $\mathbf{2 0 \%}$ \\
\hline Volume $\left(\mathbf{m}^{\mathbf{3}}\right)$ & $2,538.6$ & $5,077.1$ & $7,615.7$ & $10,154.2$ \\
Weight $(\mathbf{t})$ & $4,061.7$ & $8,123.4$ & $12,185.0$ & $16,246.7$ \\
\hline
\end{tabular}

\subsubsection{Flooding Water}

The weight of the flooding water will be calculated considering the volume of the wreck, which remains flooded after emerging from the surface of the sea. This 
weight is added to the total weight of the shipwreck only when the wreck is out of the water, because at that stage it is no longer counteracted by the buoyancy. The exact calculation of the flooded volume of the ship is extremely difficult. Therefore, five different scenarios have been developed to take into account the uncertainty surrounding the value of the flooded volume Table 4 shows the results of the calculations of the weight of flooded water for the different scenarios.

Table 4: Scenarios for the weight of flooded water.

\begin{tabular}{clllll}
\hline & \multicolumn{5}{c}{ Percentage of Ship's Volume Flooded } \\
& $\mathbf{1 0 \%}$ & $\mathbf{2 0 \%}$ & $\mathbf{3 0 \%}$ & $\mathbf{4 0 \%}$ & $\mathbf{5 0 \%}$ \\
\hline Volume $\left(\mathbf{m}^{\mathbf{3}}\right)$ & 5,077 & 10,154 & 15,231 & 20,308 & 25,386 \\
Weight (t) & 5,221 & 10,442 & 15,662 & 20,883 & 26,104 \\
\hline
\end{tabular}

\subsubsection{Suction of the seabed}

One of the initial assumptions of this case study is that the seabed in the vicinity of the illustrative wreck is viscous with finely grained sand and that the embedment depth of the ship is $2 \mathrm{~m}$. In a real-world operation this data would have been collected during a thorough on-site shipwreck survey.

Consequently, the soil bearing strength $\left(q_{u}\right)$ of the seabed is calculated at $287.28 \mathrm{kPa}^{9}$

The next step is to calculate the surface of the ship in contact with the seabed $(A)$, which is equal to the wetted surface area of the ship for a draught of $2 \mathrm{~m}$. Using the information contained in the stability booklet, the wetted surface area of the ship is found to be $1,145.80 \mathrm{~m}^{2}$.

By substituting the soil bearing strength of the seabed and the wetted surface area of the ship in Eq. (2) the bearing capacity of the seabed can be calculated.

After estimating the soil bearing capacity, the force required for immediate breakout of the wreck from the seabed is calculated. For this purpose we need to calculate the equivalent breadth $(B)$ and the embedment depth $(D)$ of the wreck.

For calculating the equivalent breadth $(B)$, it is assumed that the area of the ship in contact with the seabed $(A)$ is a rectangular shape with the same area and length equal to the length of the ship, namely $\mathrm{L}=$ $142.95 \mathrm{~m}$. The equivalent breadth $(B)$ is therefore calculated as a function of the area $(A)$ and the length (L) and it equals $B=8.02 \mathrm{~m}$.
The embedment depth $(D)$ is calculated as a function of the displaced volume of the seabed soil $(V)$, which is equal to the volume of water the ship displaces at a draught equal to $D$. Using the information contained in the stability booklet of the ship, the displacement volume for a $2 \mathrm{~m}$ draught is $3,871.65 \mathrm{~m}^{3}$. The embedment depth is therefore calculated as a function of the volume $(V)$ and the area $(A)$ and it equals $D=3.38$ $\mathrm{m}$.

Substituting the above in Eq. (3) the immediate breakout force is $F_{I B}=229,001.9 \mathrm{kN}$ or $23,343.70 \mathrm{t}$.

\subsection{Wreck removal approaches}

For the particular illustrative case study, the method of restoring buoyancy is not (practically) feasible due to the large depth $(135 \mathrm{~m})$ of the shipwreck and the size of the sunken ship.

Therefore, removing the wreck by mechanical means is deemed as the appropriate method to be employed. Two approaches will be examined: (i) in which the wreck is removed in one piece and (ii) in which the wreck is cut into several pieces and then the pieces are removed separately.

There are three key stages in the removal operation, namely:

1. Breaking the wreck out of the seabed.

2. The time period it takes to lift the wreck from the seabed up to the surface of the sea.

3. When the wreck is completely out of the sea.

In each of these stages the weight of the wreck is different due to the different forces that are applied. This fact affects the selection of the lifting equipment to be used in the operation. In particular, the required lifting capacity must be determined from the worst stage, in terms of wreck weight, which is when the wreck has emerged from the surface of the sea and the buoyancy has no effect. This point will be illustrated below.

\subsubsection{Lifting the wreck in one-piece}

Initially, the required force must be calculated for each of the key stages of the wreck removal operation. Table 5 shows the results from the respective calculations. The weight of the sediments has been calculated as extending in $20 \%$ of the ship's volume (see Table 3 ), 
while the weight of the flooding water has been calculated as $50 \%$ of the ship's volume (see Table 4). For both of these parameters, the calculations presented here are the worst of the previously considered scenarios. However, the same calculations have been conducted for each of the scenarios.

Table 5: The weight of the shipwreck for each stage of the operation.

\begin{tabular}{lccc}
\hline \multicolumn{1}{c}{ Force $(\mathbf{t})$} & Stage 1 & Stage 2 & Stage 3 \\
\hline Wreck & $11,077.3$ & $11,077.3$ & $11,077.3$ \\
Sediments & $16,246.7$ & $16,246.7$ & $16,246.7$ \\
Plating Buoyancy & $-1,703.2$ & $-1,703.2$ & - \\
Required for & $23,343.8$ & - & - \\
immediate Breakout & & & \\
Flooding Water & - & - & $26,103.6$ \\
\hline \multicolumn{1}{c}{ Total } & $\mathbf{4 8 , 9 6 4 . 6}$ & $\mathbf{2 5 , 6 2 0 . 8}$ & $\mathbf{5 3 , 4 2 7 . 6}$ \\
\hline
\end{tabular}

The next step is the selection of the derricks or sheer legs, based on the required lifting capacity. For this approach it was concluded that four derricks or sheer legs of the highest lifting capacity would be needed. The cost of the operation is outside the scope of this paper and has not been considered as a parameter for the selection of the lifting equipment. The capacities and dimension particulars for each one are shown in Table 6.

It is noted that the total available lifting capacity $(L C)$ is not enough to immediately break out the wreck from the seabed. This does not mean that the selected lifting equipment is not adequate for this operation, but rather that the completion of Stage 1 will take more time. The respective calculations are presented below.

Table 6: The main particulars of the derricks used in the one-piece approach.

\begin{tabular}{|c|c|c|c|c|}
\hline & $\begin{array}{c}\text { Lifting } \\
\text { Cap. }\end{array}$ & Length & Breadth & Draught \\
\hline & $(\mathbf{t})$ & (m) & (m) & (m) \\
\hline Thialf & 14,200 & 201.6 & \multicolumn{2}{|c|}{$88.411 .8-31.6$} \\
\hline Sapiem & 14,000 & 198.0 & \multicolumn{2}{|c|}{$87.010 .5-27.5$} \\
\hline Svanen & 8,700 & 102.6 & 71.8 & - \\
\hline DCV Hermond & 8,165 & 154.0 & \multicolumn{2}{|c|}{$86.011 .5-28.2$} \\
\hline Total & 45,065 & & & \\
\hline
\end{tabular}

Below are the calculations for the time needed to break out the wreck from the seabed, as described in a previous section of this paper.

The applied breakout force is calculated by Eq. (4), substituting the available lifting capacity (Table 6) and the respective weights (Table 5) $F_{A P}=8,177.5 \mathrm{t}=$ $80,225.7 \mathrm{kN}=18,035,537 \mathrm{p}$.

The average breakout pressure applied to the sediment is calculated by taking into account the applied breakout force and the contact area of the wreck to the seabed $(A)$. Therefore, the result is $p=1,452.5 \mathrm{psf}$.

- $\quad$ The breakout time parameter is $T=4.17 \cdot 10^{6}$,

- The equivalent embedment depth is $D=3.38 \mathrm{~m}=$ $11.09 \mathrm{ft}$,

- The equivalent breadth of the wreck is $B=8.02 \mathrm{~m}$ $=26.30 \mathrm{ft}$.

Inserting the previously mentioned numbers into Eq. (5) the breakout time in minutes is $t_{b}=62,781 \mathrm{~min}$, which translates to about 1,046 hrs or 44 days.

The calculated breakout time will increase the total time required, which in turn would increase the associated cost for the operation. Additionally, longer operation duration might also pose problems connected to the availability of the required equipment. Breakout time may be reduced by using equipment with higher lifting capacity. For the particular case however, the location of the wreck, as seen in Figure 3 (set up of the employed equipment), does not allow for the use of equipment with larger dimensions. Also, using larger equipment with higher operating costs may render the operation not feasible from a cost-benefit point of view.

For Stage 3 of the operation the required lifting capacity is much higher (58\%) than the available, including the $25 \%$ safety factor. This indicates that while the wreck emerges from the sea surface, an appropriate amount of flooding water should be pumped out of the wreck. The problem with this approach lies in the synchronization of the derricks or the sheer legs in order to stabilize the wreck during the pumping operations.

Additional challenges with regards to the lifting of the shipwreck in one-piece are the following:

- An extremely large barge is needed for the transportation of the wreck after the removal operation, 
- The wreck in one-piece will have a large wind profile area. Consequently the prevailing wind conditions might greatly influence the stability of both the wreck and the derricks, which is a major risk factor to the operation in general,

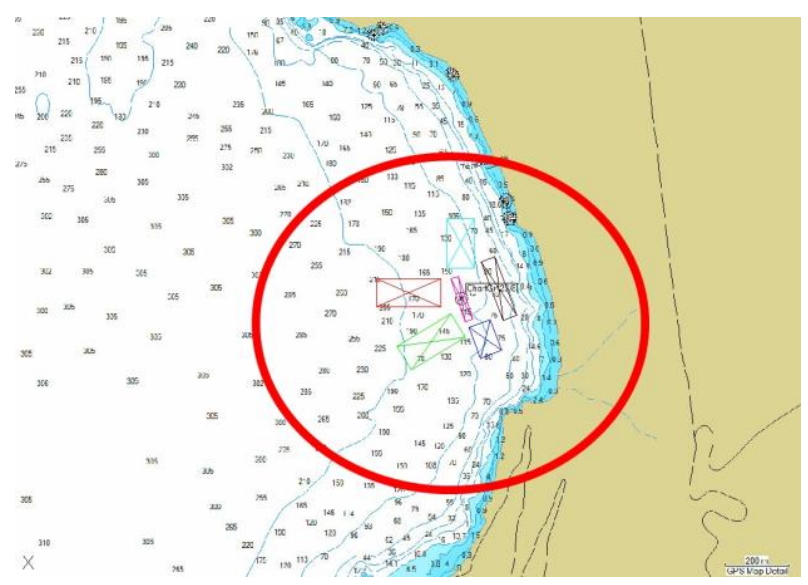

Fig. 3: The location of the wreck and the setup of the four derricks and the barge.

- The use of four or five high capacity derricks or sheer legs simultaneously will add greatly to the complexity and the cost of the setting up of the operation, which will be largely dependent on the equipment availability (this might cause an insuperable problem to the overall effort).

For the reasons mentioned above, lifting the wreck in one-piece is considered as (practicably) a not feasible option and therefore, cutting the sunken vessel in multiple pieces will be further studied hereafter in this paper.

\subsubsection{Lifting the wreck in multiple pieces}

When considering the lifting of the sunken ship in multiple pieces, the wreck will be cut into several parts as it lies on the seabed, which can also be translated into the use of fewer and of lower capacity lifting equipment.

The benefits of this approach include cutting down on operational costs, increasing flexibility with regards to the topological positioning in the vicinity above the shipwreck, and the overall simplification of the planning stage of the operation. The downside is the increase in the total time needed for the operation due to the cutting process. The details of this approach as applied to the particular illustrative case study are described below.

Hence, it comes out that one high lifting capacity sheer leg will be used; in particular, the selected one has a lifting capacity of $4,536 \mathrm{t}$. For the cutting process, the use of a steel wire rope is promoted, which is preferable against the cut with a steel chain, this way, the hull pieces are more cleanly cut and with a higher precision. Furthermore, steel chains will be employed for securing and lifting each piece up to the surface. It is important that the steel chains are positioned on the appropriate longitudinal points of the hull, which are the locations of the web frames.

Additionally, compared to lifting the wreck in one piece, a significantly smaller barge for transporting the individual wreck pieces will be required. This is due to the fact that once each piece has been lifted it will be immediately transported for scrapping. The same procedure was followed in the removal operation of the car carrier Tricolor ${ }^{18}$, which sank after colliding with the containership Cariba (2002) in the English Channel.

Because of the inherent uncertainty in determining the weight of the sediments and the flooding water in the wreck's hull, as described in previous sections of this paper, four case scenarios will be examined (Figure 4). Scenario 1 includes the same weights as for the lifting of the wreck in one-piece and will be used as a reference scenario for the evaluation of the other developed scenarios. Moreover, this scenario is considered to be the worst case because it overestimates the flooding water and weight of sediments, as it does not account for the outflow of water and reduction in sediments, which will occur during the lifting process of each hull piece.

After defining the total weight of the wreck, the next step is to answer the question: in how many pieces should the wreck be cut? The maximum weight of each piece will be determined by the available lifting capacity, considering a $25 \%$ safety factor ${ }^{8}$. The longitudinal load diagram of the wreck will determine the maximum length of each piece when it will be above the surface of the sea, which is the worst stage of the removal operation in terms of the forces applied on the hull parts.

This method is differentiated from the one considering the lifting of wreck in one piece with respect to the necessary stages prior to the lifting 
process. The first stage is the cutting process, which is assumed to last about $120 \mathrm{~h}$ for each piece. The same amount of time was used for the cutting of the engine

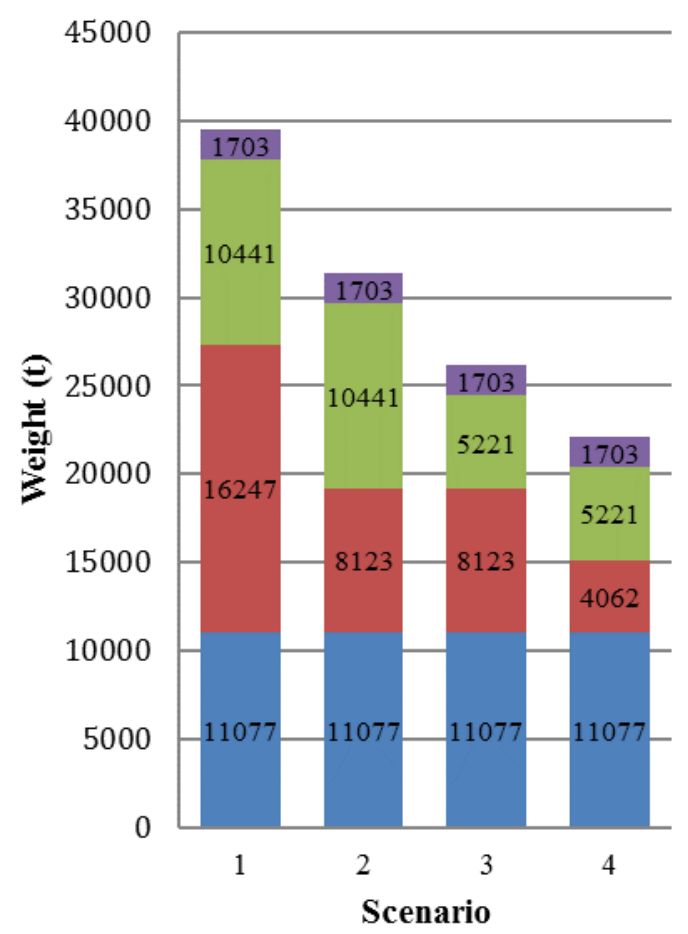

$\varpi$ Ship $\backsim$ Sediments $\backsim$ Fl. Water $\backsim$ Buoyancy of Pl.

Fig. 4: Weight scenarios differentiating sediments and flooded water.

room of the car carrier Tricolor ${ }^{18}$. This is followed by gradually applying the lifting load on the steel chains in order to avoid multiple material failures during the lifting process. Typically the time needed to apply the full lifting load can be assumed to be about $1 \mathrm{~h}$ for each piece, which is considered an adequate amount of time. The next stage is breaking out the pieces from the seabed. Prior to commencing the lifting process and after the breakout, each piece needs to be secured and the steel chains surveyed. For this case study it was assumed that the securing stage will last about $1 \mathrm{~h}$ for each piece, which is again considered an adequate amount of time. After the lifting arrangement has been stabilized, the lifting process towards the sea surface may begin.

This approach is complemented by a preliminary structural strength analysis for each piece, taking into account the exact positions of the steel chains and the respective weight distribution.

The accurate estimation of the weight distributions for sediments, buoyancy of plating, the breakout force and flooding water is extremely difficult. However, they can be approximated by trapezoidal distributions, based on the length of the parallel midbody of the shipwreck. The load diagrams for each stage of the removal operation are calculated as the sum of the individual weight distributions, as seen in Figure 5 for the reference Scenario. Based on the available lifting capacity and the load diagrams, it was concluded that the wreck would be cut into at least 12 pieces. If the wreck was cut into less than 12 pieces, then the available lifting capacity would not be sufficient to lift each piece.

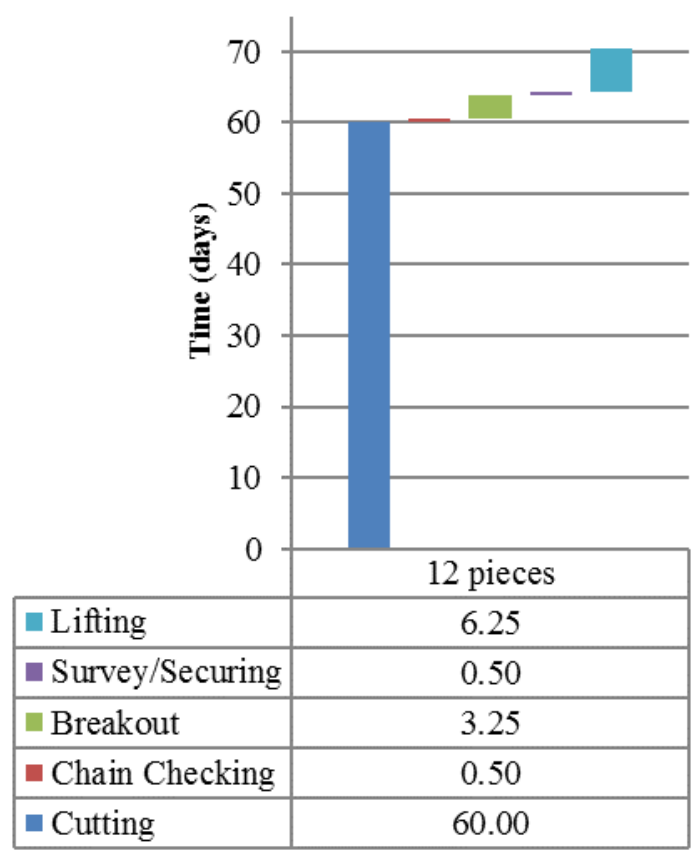

Fig. 5: Scenario 1 - Distribution of time for each stage of the operation without the $30 \%$ increasing factor.

For the estimation of the total required time of the removal operation it was assumed that the lifting speed equals $3 \mathrm{~m} / \mathrm{h}$, which can be considered as a typical one and was the lifting speed of the stern section of the containership MSC Napoli ${ }^{12}$. Therefore lifting each piece will take about $750 \mathrm{~min}$ or $12.5 \mathrm{~h}$, considering that the wreck lies in $135 \mathrm{~m}$ depth. The duration in days for 
each stage of the reference scenario is shown in Figure 6.

It is noteworthy that the total breakout time equals to $7.5 \%$ of the required time in the choice of lifting the wreck in one piece. This difference is due to the fact that the required breakout force is much smaller for each individual piece than for the whole ship.

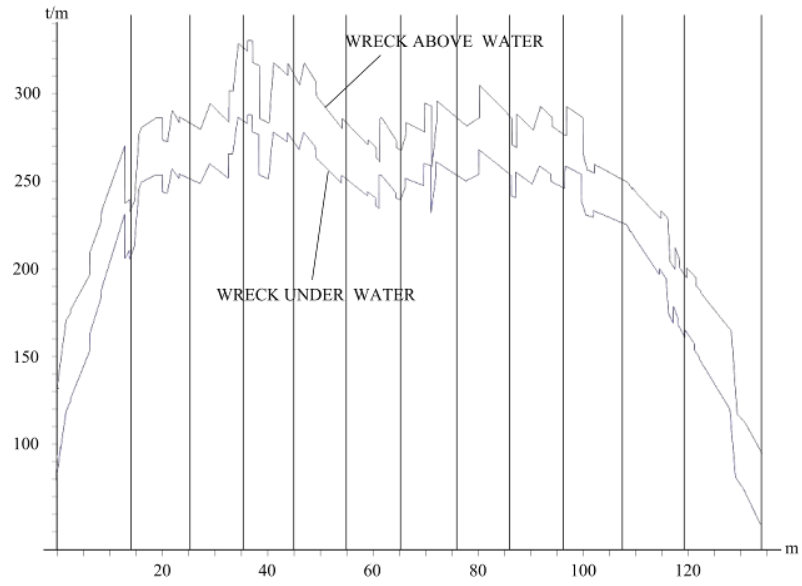

Fig. 6: Weight Distributions of shipwreck above and below the sea surface. The vertical lines mark the cutting points of the wreck pieces for the reference scenario.

The estimation of the total time required for the removal operation does not include an analytic calculation for the following:

- Preparation and setting-up,

- Deployment of steel cutting wires and lifting chains,

- Draining sea water from each piece while emerging from the sea surface,

- Positioning each piece on the barge.

The required time periods for the above are not fixed and are affected by many contributing factors. Therefore, for this approach, an increasing factor of $30 \%$ will be applied to the total calculated time for the operation.

Figure 7 depicts the total required time in relation to the number of wreck pieces for each implemented scenario. The operation in the context of Scenario 1, where the wreck is cut into 12 pieces, would take about 92 days and is used (only) as reference. The minimum number as well as the length of the pieces for each scenario has been based on the respective load diagrams so as the weight of each piece does not exceed the available lifting capacity. For numbers of pieces greater than the minimum for each scenario, they have been assumed to be of equal length. For example, for Scenario 4 the minimum number of pieces is 7 (Figure 7 ) and thereon it has been assumed that the wreck is cut into $8,9,10,11$ and 12 pieces of equal length, Considering Scenarios 2, 3 and 4, it appears that the optimum number of pieces is 10 . At this point, the number of pieces in Scenario 2 has been determined from the load diagram and the length is not the same for each one, while in Scenarios 3 and 4 the pieces are of equal length. This amounts to the operation taking longer in Scenario 3, because the available lifting capacity is not being efficiently used, as some pieces may be much lighter than others.

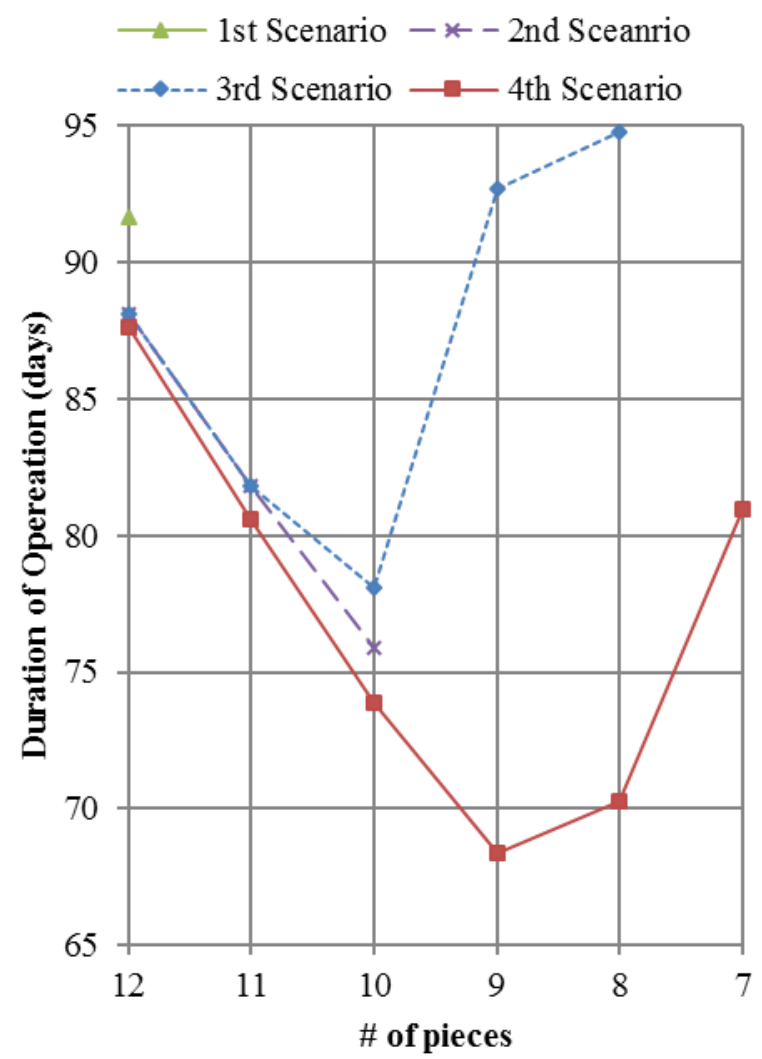

Fig. 7: Total time for each scenario as a function of the number of wreck pieces, including the $30 \%$ increasing factor.

\subsection{Discussion}

A defining factor for the feasibility of wreck removal operations is the total cost. In the preliminary planning stage it is difficult to estimate the cost due to the lack of publicly available information, both for the required equipment as well as for the services rendered by the involved parties. However, it is important to 
complement the setting up of a wreck removal operation with a detailed cost-benefit analysis.

The results presented in this paper are in accordance with real-world operations such as the removal of the car carrier Tricolor, which was cut into 9 pieces $^{18}$. The methodology of this paper suggests cutting the wreck of the case study into 10 pieces, which is the optimum number derived from the scenario based analysis. The difference between the two cases is due to the fact that the Tricolor was removed almost immediately after sinking and consequently there had been a very small amount of sedimentation on the hull. On the other hand, the wreck of the case study is assumed to have been underwater for a long time, which means that the accumulated sedimentation has increased its weight considerably.

Furthermore, the methodology outlined in this paper is important in order to evaluate a number of alternative wreck removal methods and select the most feasible one by taking into account the following parameters:

- Environment of the wreck removal operation,

- Weight of the shipwreck, and

- Estimated total time.

The methodology of this paper is a scenario based approach in order to incorporate the uncertainty element of the analysis. The underlying uncertainties during the planning phase of a wreck removal operation lie mainly in the calculation of the weight of the shipwreck, which will determine the required equipment. In particular, this paper developed scenarios for the weight of the sediments accumulated on the hull as well as the flooding water inside the wreck, The scenario based approach is necessary due to the difficulty in collecting reliable data from reports and even on-site surveys. Using the illustrative case study, this paper outlines the key stages of the planning phase of a wreck removal operation.

\section{Conclusions}

A wreck removal operation is a complex subject that can be affected by multiple factors. One of the main defining factors is the prevailing weather conditions on the location of the shipwreck, which increases the uncertainty as it can delay, halt or even postpone the entire operation. The planning is also greatly affected by the availability of the needed equipment and by the running costs; these factors determine the employed method and the total required time, simultaneously.

The mostly used wreck removal method is lifting by mechanical means. The advantages thereof include less preparation time, greater flexibility for the operation, which leaves room for technical innovation, and improved controllability of the wreck during the lifting stage.

Additionally, a wreck removal operation starts and ends with a thorough and detailed survey of the shipwreck in order to gather as much information as is practicably feasible to better define the problem and find the best solutions.

A wreck removal operation is a crisis with challenging solutions because it cannot be standardized into a rigid frame. This is due to the fact that each shipwreck has unique characteristics and must be studied individually and with extreme caution, so as to obtain the best possible results in terms of efficiency, safety and environmental friendliness.

\section{References}

1. G. G. McGrath et al., The investigation to identify the SS Jacob Luckenbach - using technology to locate a hidden source of oil that cause years of impacts and the future implications of sunken shipwrecks, (International Oil Spill Conference, 2003)

2. J. Wilkins, U.S. Navy Salvage report USS Mississinewa Oil Removal Operations, (Naval Sea Systems Command, 2004)

3. J. Michel et al., Potentially Polluting Wrecks in Marine Waters, (International Oil Spill Conference, 2005)

4. M. J. Barrett, Spatial tools and analysis of WWII shipwrecks, (Master's Project, Nicholas School of the Environment, Duke University, 2011)

5. I. Hassellöv, Pre-study of shipwreck assessment and remediation, (The Alliance for Global Sustainability, Göteborg, 2007)

6. N. P. Ventikos, K. Louzis and A. Koimtzoglou, The Shipwrecks in Greece are going Fuzzy: A Study for the Potential of Oil Pollution from Shipwrecks in Greek Waters, (Human and Ecological Risk Assessment: An International Journal, 2013)

7. H. Landquist et al., Evaluating the needs of risk assessment methods of potentially polluting shipwrecks, (Journal of Environmental Management, 2013)

8. W. I. Milwee, Modern Marine Salvage, (Cornell Maritime Press, Maryland, 1996).

9. C. A. Bartholomew and M. Bert and R. Hooper, (U.S. Navy Salvage Engineer's Handbook $1^{\text {st }}$ revision, (U.S Navy Sea Systems Command, 2008)

10. Smit, The Salvage of the Kursk, (Technical Report) 
11. V. Streeter, E. Wylie and K. W. Bedford, Fluid Mechanics, $9^{\text {th }}$ edn. (McGraw - Hill, 1998)

12. P. Glerum, Removal of Napoli Stern Section, (The $12^{\text {th }}$ Annual Salvage \& Wreck Removal Conference, London, 2009)

13. US Navy, Salvor's Handbook, (Naval Sea Systems Command, 2004)

14. A. Winer and W. F. Searle, Plastic Foams for Marine Salvage, (Salvage Engineer's Journal, August 1970), pp. 97-110

15. J. Porter, Removal Men, (Lloyd's List Australia - The Daily Commercial News, Sep. 10, 2009)

16. D. Parrott, Removal of the New Carissa Stern Section, (The $12^{\text {th }}$ Annual Salvage \& Wreck Removal Conference, London, 2009)

17. Wisjmuller Salvage bv, Mission: (Re-)Floating Drydock, (Svitzer-Wisjmuller, DVD)

18. J. C. Burvingt, The Tricolor Experience in the Framework of the Contingency Plan Mancheplan, (Cherbourg Armees: Prefecture Maritime de la Manche et de la Mer du Nord) 